\title{
Las aguas turbias de la megaminería en México
}

\section{FEDERICO GUZMÁN LÓPEZ*}

En el capitalismo mexicano del siglo Xxı la gestión estatal del despojo siembra economías de enclave dedicadas a la extracción y la exportación de recursos naturales y le concede el uso preferente a recursos vitales (como el agua) a favor de los megaproyectos en detrimento de las necesidades humanas. La expansión de la megaminería transcurre por una división internacional del trabajo que implementa en los territorios intervenidos el despojo hídrico y la mercantilización del agua, a la vez que provoca la depredación del patrimonio natural de las comunidades y deriva en efectos destructivos y degenerativos del medio ambiente.

* Egresado del Doctorado en Estudios del Desarrollo,

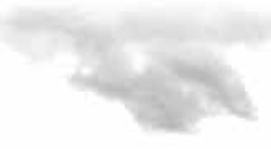




\section{Introducción}

Estudiar el nexo entre la megaminería y el despojo hídrico en México, en el marco del desarrollo neoliberal del sistema capitalista, es el objetivo de este artículo. Se argumenta que el saqueo de las aguas subterráneas y superficiales ocasionó que se intensificara el modelo extractivo en todo el territorio, que ha sido transformado en economía de enclave mediante una política de Estado de despojo. Así, los megaproyectos que basan su actividad productiva en la extracción y la explotación de recursos naturales de origen mineral provocan la depredación del patrimonio natural de las comunidades y tienen distintos impactos ambientales desfavorables de diversa índole, entre los que destaca la sobreexplotación de los acuíferos y las fuentes de agua.

El documento se presenta en dos secciones. La primera expone el papel que desempeñan los principales bancos del mundo y las empresas transnacionales en el control del mercado del agua a escala internacional. En la segunda se examinan el despojo hídrico ocasionado por la megaminería y los tipos de uso de aguas subterráneas y superficiales. También se profundiza en el consumo del agua con datos empíricos por entidad federativa y empresas mineras. Por último, se relaciona dicha información con las afectaciones sociales directas que vulneran el derecho humano al agua de los mexicanos.

\section{Mercantilización del agua en el contexto internacional}

En el contexto internacional, uno de los signos vitales del periodo neoliberal del sistema capitalista en México se manifiesta con la mercantilización del agua, cuya problemática se teje por el binomio escasez y contaminación del recurso hídrico. Ello ocasionó una tendencia a

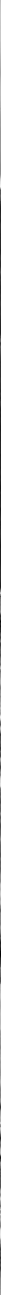


ejercer un control monopólico sobre las primordiales fuentes de extracción y suministro de agua en el planeta, con incremento en la participación del capital privado, avalado por organismos internacionales como el Banco Mundial (BM) a través de organizaciones no gubernamentales como el Fondo Mundial para la Naturaleza (WWF, por sus siglas en inglés).

La privatización de servicios de agua potable y saneamiento cobró fuerza en la década de los 1990, lo que dificultó aún más el acceso al agua y elevó los costos. Ruiz explica que dicho proceso se ha dado de diversas maneras: ${ }^{1}$ abasto municipal de agua potable para consumo humano en zonas urbanas, trasvase de aguas mediante la desviación de cauces naturales, construcción de megaproyectos de capital global de represas, mercantilización del agua embotellada, contaminación del agua por la industria extractiva minera y petrolera y control de la comercialización y patentes de la tecnología del agua. ${ }^{2}$

Lo anterior ha sido posible gracias a los acuerdos de cooperación entre la Unión Europea y América Central y la región Andina. El punto central de la agenda fue permitir la mercantilización del agua y los energéticos para consolidar el control de mercados del agua que ejercen en tales regiones las transnacionales Suez (de origen francés); Iberdrola, Aguas de Barcelona, Unión Fenosa (de España); y Biwater (de Inglaterra), que han dominado el mercado del agua en varias economías latinoamericanas. Al respecto, Valdomir argumentó que

\footnotetext{
${ }^{1}$ Carmelo Ruiz, «La privatización del agua en América latina», 2005, http://www.ecoportal.net/Temas-Especiales/ Agua/La_Privatizacion_del_Agua_en_America_Latina ${ }^{2}$ Federico Guzmán, Economía política del despojo territorial. Megaminería a cielo abierto en Zacatecas bajo el capital global, 1982-2014, Zacatecas, 2016, 357 p. Tesis (doctorado en Estudios del Desarrollo), Universidad Autónoma de Zacatecas.
}

el ejemplo más claro en este sentido es Chile; este país (...) que cuenta con los TLC suscritos con Estados Unidos y la Unión Europea (entre muchos otros), tiene privatizados y concentrados los denominados «derechos de agua» en grandes empresas transnacionales como la española Endesa, principal generadora de energía eléctrica, mineras como las inglesas Río Tinto y BHP Billiton y de distribución de Aguas de Barcelona (...) En Perú, las «dueñas» del agua son las transnacionales mineras como Yanacocha; la contaminación y destrucción de los cursos de agua, el aprovechamiento indiscriminado del bien para la extracción de metales y la total impunidad con que operan estas empresas. ${ }^{3}$

Actualmente, se disputa el control de la cadena de extracción y el suministro de agua en beneficio del capital privado estadounidense controlado por Monsanto Wells, Enron Springs, ITT Corporation y Bechtel Co.; o europeo, en especial por Aguas de Valencia y Unión Fenosa Acex (de España), Suez Environnement/División Ondeo, Vivendi y Veolia Environnement (de Francia), o Thames Water, United Utilities y Severn Trent (de Inglaterra). El saqueo hídrico (en las modalidades de almacenamiento, distribución y potabilización) se asegura mediante la privatización de acuíferos, cuencas hidrológicas y la infraestructura necesaria (represas, trasvases, plantas tratadoras). ${ }^{4}$

Delgado indicó que en el caso de América del Norte los gobiernos de México, Estados Unidos y Canadá han transferido la rectoría sobre las aguas nacionales al capital privado, al subordinar la gestión del agua a los intereses comerciales planteados en el marco de los tratados comerciales como el Tratado de Libre

\footnotetext{
${ }^{3}$ Sebastián Valdomir, «El agua continúa en la mira de las transnacionales», 2008, http://www.alainet.org/es/active 130967

${ }^{4}$ Etc Group, «Las 10 principales empresas de agua del mundo», 2013, http://www.etcgroup.org/es/content/las-10 -principales-empresas-de-agua-del-mundo
} 
del agua, con distintos instrumentos como la compra de derechos de agua y tecnologías e infraestructura de los servicios para el suministro del recurso hídrico. ${ }^{11}$ La trama de capital extractivo para el saqueo del agua implica la articulación de capital ficticio en Wall Street, por medio de la atracción de bancos $\mathrm{y}$ fondos de cobertura, fondos de pensiones y otras empresas de capital subsidiario transnacional que fungen como proveedores de tecnología del agua. Referente al tema, El Robot Pescador sostiene:

Los elitistas multimillonarios y los grandes bancos de Wall Street están comprando agua por todo el mundo a un ritmo sin precedentes. Grandes conglomerados bancarios como Goldman Sachs, JP Morgan Chase, Citigroup, UBS, Deutsche Bank, Credit Suisse, Macquarie Bank, Barclays Bank, Blackstone Group, Allianz y HSBC, entre otros, están consolidando su control sobre el agua de todo el planeta. Magnates ricos como T. Boone Pickens, el expresidente George H.W. Bush y su familia, Li Ka-shing de Hong Kong, Manuel V. Pangilinan y otros multimillonarios filipinos, así como muchos otros, están comprando miles de hectáreas de tierra con acuíferos, lagos, derechos sobre el agua. ${ }^{12}$

Es decir, la situación cada vez más se vuelve irreversible debido a la afectación, a la cantidad y calidad de líquido disponible; cuando se mercantiliza el agua se promueven efectos económicos y sociales adversos para la mayoría de la población, en la medida que se propicia una tendencia a incrementar el precio por el acceso a ella. De forma paralela, implica que

${ }^{11}$ Amigos de la Tierra Internacional, «Informe denuncia fi-
nanciarización del agua en vísperas de conferencia minis-
terial de la OMC», 2013, http://www.foei.org/es/noticias/
informe-denuncia-financiarizacion-del-agua-en-vispe-
ras-de-conferencia-ministerial-de-la-omc
${ }^{12}$ «Alarma mundial: los grandes bancos se apoderan del
agua de todo el planeta», El Robot Pescador, 2015, https://
elrobotpescador.com/2015/03/25/alarma-mundial-los-
grandes-bancos-se-apoderan-del-agua-de-todo-el-planeta/ los seres humanos que viven en condiciones de pobreza y pobreza extrema, y que rondan sobre la economía de subsistencia, se enfrentan a la dificultad cotidiana del acceso libre al agua. García reconoce al agua como

un elemento trascendental para el desarrollo, ya que constituye un ingrediente primordial en la generación de medios de subsistencia rurales, el cultivo de alimentos, la producción de energía (...) y para asegurar la integridad de los ecosistemas. ${ }^{13}$

Su relevancia es tal que las disputas podrían traducirse en conflictos violentos en diversas partes del mundo, como ocurrió en Bolivia en 2000. ${ }^{14}$

\section{Despojo hídrico causado por la megaminería en México}

La mercantilización del agua también sucede en México, en específico para uso de la megaminería. De acuerdo con Aguilar, se «pone la primacía del mercado por sobre el ser humano» ${ }^{15}$ en la disputa por el acceso y control del recurso hídrico. Dicha realidad de escasez de agua

ha agregado una nueva dimensión al fenómeno migratorio en México: la ecomigración; por lo que ubicamos una vinculación estrecha entre el agotamiento del agua y el traslado de la población a otros lugares en busca de satisfacer sus necesidades colectivas. ${ }^{16}$

\footnotetext{
${ }^{13}$ Álvaro García, El derecho humano al agua en México, Zacatecas, Instituto Internacional del Derecho y el Estado/ Universidad Autónoma de Zacatecas, 2016, pp. 5-6.

${ }^{14}$ Michele Bertelli, Javier Sauras y Félix Lill, «La guerra interminable: 15 años de la lucha por el agua en Bolivia», El País, 13 de julio de 2015, http://elpais.com/elpais/2015/07/13/ planeta_futuro/1436796771_984802.html

${ }^{15}$ Erick Alejandro Rafael Aguilar, «Genealogía del derecho al agua en México», Impluvium, núm. 4, enero-junio 2015, http://www.agua.unam.mx/assets/pdfs/impluvium/ numero04.pdf

${ }^{16}$ Álvaro García, op. cit., p. 13.
} 


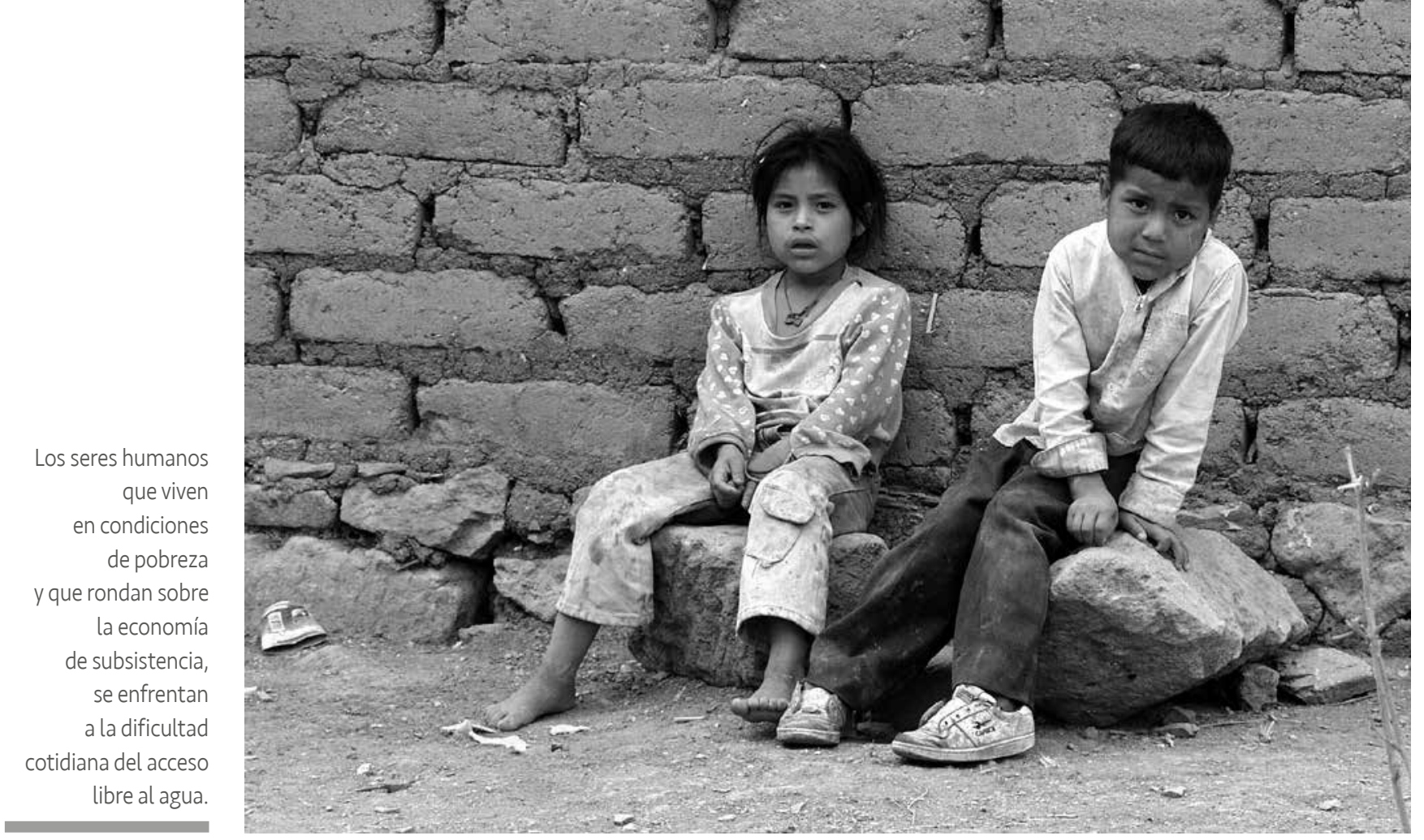

Fenómeno social que ocurre con mayor intensidad en entidades federativas con gran presencia de la minería; es el caso del semidesierto zacatecano, cuya población emigra hacia Monterrey y Saltillo, o de Chihuahua, pues en 2015 comenzó un éxodo de 90 mil personas de la comunidad agrícola menonita hacia Argentina, Canadá, Colombia, Paraguay y Rusia por la falta de disponibilidad de agua y las constantes disputas con agricultores mexicanos y la industria extractiva. ${ }^{17}$

Comisión Nacional del Agua (Conagua) indica que en todo el territorio nacional, según los datos del Registro Público de Derechos de Agua (Repda), se han otorgado 397 mil 593 títulos que amparan concesiones de extracción de aguas superficiales y subterráneas por 266 mil 694 millones 850 mil 959 m³$^{3}$. Cabe mencionar que durante 2014 se extrajeron 6.76 millones $\mathrm{m}^{3}$ de agua por segundo. ${ }^{18}$

${ }^{17}$ «Menonitas dejarán México: su país desde 1922; la razón: Chihuahua se queda sin agua», Pulso, 18 de noviembre de 2015, http://pulsoslp.com.mx/2015/11/18/menonitasdejaran-mexico-su-pais-desde-1922-la-razon-chihuahuase-queda-sin-agua/

${ }^{18}$ Comisión Nacional del Agua, «Respuesta a solicitud de acceso a información registrada mediante el Sistema Infomex mediante Folio 1610100256015», Subdirección General
La megaminería se ubica entre las industrias con mayor consumo de recursos hídricos, circunstancia que afecta la disponibilidad y calidad del agua a causa de sobreexplotación, contaminación y destrucción de fuentes de agua subterránea y superficial. Debido a los impactos de destrucción ambiental el Consejo de Minería Ambiental de la Columbia Británica advirtió que el agua ha sido considerada como

el accidente más común de la minería (...) La naturaleza de la minería incluye el consumo, el desvío y posiblemente la contaminación seria de nuestras fuentes de suministro de agua. Los cambios en la legislación, en la tecnología y en las actitudes, han comenzado a reconocer algunas de las amenazas más inmediatas, impuestas por la explotación de minerales. ${ }^{19}$

Jurídica-Gerencia de Descentralización y de Transparencia y Acceso a la Información Pública, Ciudad de México, Conagua, 2016.

${ }^{19}$ Consejo de Minería Ambiental de la Columbia Británica, «Drenaje ácido de la minería. Minería y contaminación de agua en la Columbia Británica, Canadá», 2006, p. 3, http:// miningwatch.ca/es/publications/2006/3/25/drenaje-cidode-la-miner-miner-y-contaminaci-n-de-agua-en-lacolumbia-brit 
Cuadro 1. Títulos y volúmenes de aguas nacionales concesionadas, 2015

\begin{tabular}{|c|c|c|c|c|c|}
\hline Uso & Títulos & $\begin{array}{l}\text { superficiales } \\
\text { umen de extracción } \\
\text { concesionado } \\
\left(\mathrm{mm}^{3} / a n ̃ o\right)\end{array}$ & Títulos & $\begin{array}{l}\text { as subterráneas } \\
\text { Volumen de extracción } \\
\text { concesionado } \\
\left(\mathrm{mm}^{3} / \text { año }\right)\end{array}$ & $\begin{array}{l}\text { Volumen total } \\
\left(\mathrm{mm}^{3} / \text { año }\right)\end{array}$ \\
\hline Agrícola & 30466 & 37292432513 & 136706 & 20009893285 & 57302325798 \\
\hline Generación de energía eléctrica & 124 & 182432382867 & 4 & 3515000 & 182435897867 \\
\hline Público urbano & 66759 & 5150626846 & 55776 & 7297704178 & 12448331024 \\
\hline Industrial & 468 & 4403809700 & 5083 & 1578766913 & 5982576613 \\
\hline Múltiples & 6388 & 2386128014 & 37106 & 3265683456 & 5651811470 \\
\hline Servicios & 628 & 533350860 & 6402 & 946878896 & 1480229756 \\
\hline Acuacultura & 710 & 1092823194 & 288 & 43905080 & 1136728274 \\
\hline Pecuario & 14774 & 62589700 & 20417 & 142797308 & 205387256 \\
\hline Doméstico & 1484 & 13539215 & 13936 & 24444632 & 37983847 \\
\hline Conservación ecológica & 1 & 9460800 & 0 & 0 & 9460800 \\
\hline Agroindustrial & 13 & 760263 & 55 & 2796576 & 3556839 \\
\hline Otros & 1 & 300000 & 2 & 181415 & 481416 \\
\hline Comercio & 0 & 0 & 2 & 80000 & 80000 \\
\hline Totales & 121816 & 233378204218 & 275777 & 33316646739 & 266694850959 \\
\hline
\end{tabular}

Fuente: Conagua, «Títulos y volúmenes de aguas nacionales y bienes inherentes por uso de agua», 2016, http://www.conagua.gob.mx/CONAGUA07/Contenido/Documentos/nacional.pdf

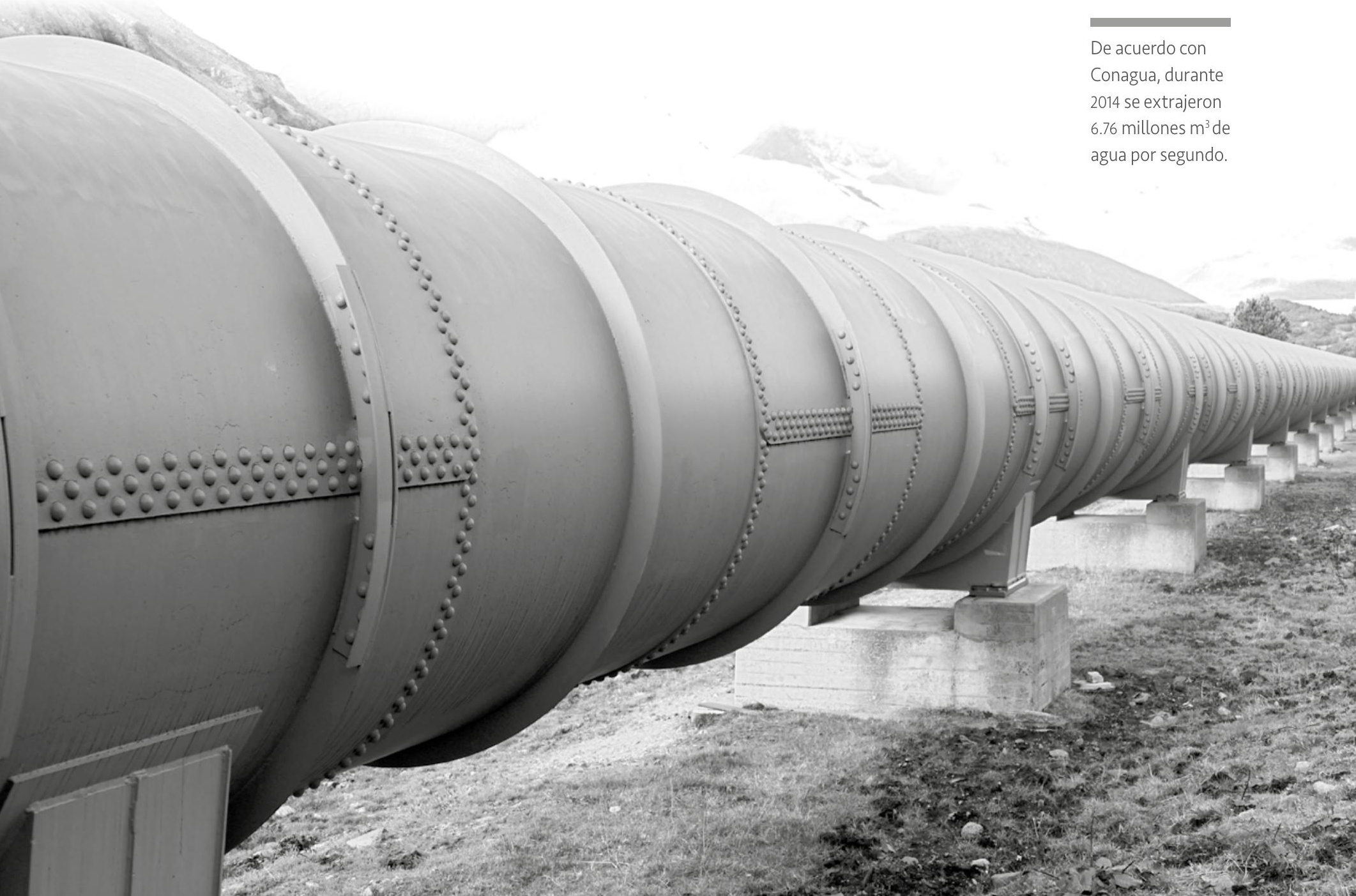


En ese sentido, Conagua informó: «Al 31 de diciembre de 2013 se reportan 106 acuiferos sobreexplotados (...) De los acuíferos sobreexplotados se extrae el 55.2 por ciento del agua subterránea para todos los usos» $.{ }^{20} \mathrm{Ca}-$ rabias y Landa destacaron que México se ubica en el lugar 106 entre 122 países en cuanto a calidad del agua; asimismo, 80 por ciento del agua subterránea es de buena calidad, mientras que en las aguas superficiales 27 por ciento es de calidad aceptable y 24 por ciento es altamente contaminada. ${ }^{21}$

Al revisar el uso de aguas superficiales y subterráneas por cada sector se identifica la proporción en la que participa la industria minera de forma comparativa con los demás. En 2014 el saqueo del agua para la industria minera ascendió a 436 millones 643 mil $287.92 \mathrm{~m}^{3}$ anuales, cifra equivalente a 7.29 por ciento de los 5 mil 982 millones 576 mil $613 \mathrm{~m}^{3}$ por año concesionados al sector industrial mexicano. Dicha cifra también equivale a la cantidad que permite abastecer las necesidades del vital líquido en el mismo año en cuatro entidades federativas: Baja California Sur, Campeche, Colima y Nayarit (véase cuadro 1). ${ }^{22}$ Cartocrítica manifiesta que

se encontraron 417 empresas mineras dentro del Repda, que se lograron agrupar en 230 grupos empresariales mineros. Un total de 1036 títulos de aprovechamiento de agua, amparando un volumen de 436 millones $643 \mathrm{mil} 287.92 \mathrm{~m}^{3}$ anuales de agua es lo que se encontró concesionado a empresas mineras. Esto es el equivalente al volumen de agua necesario para satisfacer el derecho humano al agua por

${ }^{20}$ Comisión Nacional del Agua, «Estadísticas del agua en México, edición 2014», p. 45, http://www.agua.org.mx/elagua/agua-en-mexico/datosycifrasaguaenmexico/34255estadisticas-del-agua-en-mexico-2014

${ }^{21}$ Julia Carabias y Rosalva Landa, Agua, medio ambiente y sociedad, hacia la gestión de los recursos hídricos en México, Ciudad de México, Universidad Nacional Autónoma de México/El Colegio de México/Fundación Gonzalo Río Arronte, 2005

${ }^{22}$ Comisión Nacional del Agua, «Respuesta a solicitud...». un año de 11 millones 962 mil 830 personas. Cabe recordar que en México 13.8 millones de personas no tienen acceso al agua en la vivienda. ${ }^{23}$

Con relación al saqueo del agua por la industria minera en México, Grupo México, Goldcorp y Arcelor Mittal se apropian de 44.1 por ciento del líquido. Al analizar datos del consumo de agua efectuado por la megaminería en 2001, con el concepto de huella hídrica Santacruz y Peña se refieren al volumen del agua empleado de manera directa e indirecta por determinada modalidad de extracción minera:

La minería de metales emplea 53.5 millones de $\mathrm{m}^{3}$ $\left(\mathrm{mm}^{3}\right)$ de agua, de origen superficial o subterráneo (...) y el volumen de agua residual generado se estima en $26.2 \mathrm{~mm}^{3}$, que es vertido en los cuerpos de agua o en las redes de drenaje municipales. ${ }^{24}$

Sin embargo, en 2014 hubo un crecimiento exponencial en el consumo de agua, hasta llegar a los $436.64 \mathrm{~mm}^{3}$, cifra que representó un incremento de 823.85 por ciento durante el periodo ya señalado. Al revisar la información de la distribución de concesiones de agua extraída para la industria minera por entidad federativa, Cartocrítica expuso: «La mitad del agua destinada a la minería en el país se extrae en tan sólo tres estados: Sonora (107.9 millones de $\mathrm{m}^{3} / \mathrm{a}$ ), Zacatecas (55.8 millones de $\mathrm{m}^{3} / \mathrm{a}$ ) y Michoacán (44.4 millones de mª) », ${ }^{25}$ es decir, la megaminería en Zacatecas consume más cantidad que la que se usaba en todo el país al inicio del presente siglo (véase cuadro 2).

\footnotetext{
${ }^{23}$ Cartocrítica, «Concesiones de agua para las mineras», 2016, http://www.cartocritica.org.mx/2016/concesiones-de -agua-para-las-mineras/

${ }^{24}$ Germán Santacruz y Francisco Javier Peña, «Huella gris y minería: el impacto de extracción de metales en el agua», en Rosario Pérez, Roberto Constantino e Hilda Dávila (coords.), Agua, alimentación y bienestar: la huella hídrica como enfoque integral de gestión del agua en México, Ciudad de México, Universidad Autónoma Metropolitana-Xochimilco, México, 2013, p. 225.

${ }^{25}$ Cartocrítica, op. cit.
} 
Cuadro 2. Distribución de volumen de agua concesionada a la minería por entidad federativa, 2014

\begin{tabular}{|c|c|c|}
\hline Entidad federativa & Títulos & $\begin{array}{c}\text { Volumen extraído } \\
\left(\mathrm{m}^{3} / \mathrm{a}\right)\end{array}$ \\
\hline Sonora & 202 & 107867891.30 \\
\hline Zacatecas & 98 & 55781044.00 \\
\hline Michoacán & 9 & 44387033.36 \\
\hline Chihuahua & 79 & 34249726.00 \\
\hline Coahuila & 76 & 32533757.00 \\
\hline Durango & 29 & 32187060.00 \\
\hline Veracruz & 39 & 22899913.52 \\
\hline Nuevo León & 102 & 22124726.00 \\
\hline Colima & 25 & 12019242.50 \\
\hline San Luis Potosí & 56 & 10098206.60 \\
\hline Guerrero & 23 & 8703900.80 \\
\hline Hidalgo & 31 & 8374906.75 \\
\hline Tamaulipas & 14 & 8163501.00 \\
\hline Guanajuato & 31 & 6272758.20 \\
\hline Puebla & 22 & 6233448.00 \\
\hline Tabasco & 8 & 4454014.00 \\
\hline México & 29 & 3439602.00 \\
\hline Jalisco & 36 & 2775879.00 \\
\hline Baja California & 5 & 2484759.00 \\
\hline Quintana Roo & 17 & 1644168.60 \\
\hline Baja California Sur & 6 & 1619199.00 \\
\hline Sinaloa & 8 & 1481613.70 \\
\hline Oaxaca & 6 & 1291894.72 \\
\hline Yucatán & 39 & 1208703.63 \\
\hline Tlaxcala & 7 & 950697.00 \\
\hline Morelos & 5 & 904858.60 \\
\hline Querétaro & 5 & 781080.00 \\
\hline Nayarit & 6 & 589740.00 \\
\hline Distrito Federal & 5 & 474119.00 \\
\hline Chiapas & 10 & 388060.40 \\
\hline Campeche & 7 & 215648.24 \\
\hline Aguascalientes & 1 & 42136.00 \\
\hline Total general & 1036 & 436643287.92 \\
\hline
\end{tabular}

Fuente: Cartocrítica, «Concesiones de agua para las mineras», 2016, http://www.cartocritica.org.mx/ 2016/concesiones-de-agua-para-las-mineras/
Con el propósito de dimensionar el saqueo del agua en las entidades federativas que mayor cantidad de agua han concesionado para la operación de megaproyectos de capital global de minería extractiva, debe tomarse como referencia que la Organización Mundial de la Salud (OMS) plantea como derecho humano al agua entre 50 y 100 litros diarios por persona. ${ }^{26}$ En el caso del estado de Sonora, si se considera el nivel máximo (100 litros diarios), los 107.86 millones $\mathrm{m}^{3}$ de agua que consume anualmente la megaminería serían suficientes para abastecer del vital líquido a 2 millones 955 mil 284 personas en ese periodo, cifra que representa 110.9 por ciento de los 2 millones 662 mil 480 habitantes de la entidad. Así, en Zacatecas, los 55.78 millones $\mathrm{m}^{3}$ permitirían abastecer a $1 \mathrm{mi}$ llón 528 mil 247 personas, equivalente a 102.5 por ciento de sus habitantes..$^{27}$ Sobresale el impacto ambiental que deben asumir Sonora y Zacatecas (primero y segundo lugar nacional de extracción de minerales metálicos, respectivamente): el excesivo consumo de agua de la megaminería, superior al de toda la población que habita en las dos entidades federativas.

En otros estados donde la industria minera adquiere relevancia, el saqueo del agua ocurre en menor proporción. Por ejemplo, en Michoacán se otorgaría agua potable a 1 millón 216 mil 83 personas, equivalente a 27.9 por ciento de los 4 millones 351 mil 37 habitantes; en Chihuahua, a 938 mil 348 personas, equivalente a 27.5 por ciento de los 3 millones 406 mil 465 habitantes; en Durango, a 881 mil 837 personas, correspondiente a 54 por ciento de 1 millón 632 mil 934 de habitantes. En el acaparamiento del agua concesionada a la industria minera participan empresas transnacionales (véase cuadro 3).

\footnotetext{
${ }^{26}$ Organización de las Naciones Unidas, «El agua fuente de vida 2005-2015», 2014, http://www.un.org/spanish/waterforlifedecade/human_right_to_water.shtml

${ }^{27}$ Instituto Nacional de Estadística, Geografía e Informática, «XIII Censo General de Población y Vivienda 2010», 2010, http://www3.inegi.org.mx/sistemas/iter/default.aspx?ev=5
} 
Cuadro 3. Principales empresas mineras que despojan el agua en México, 2014

\begin{tabular}{|c|c|c|}
\hline Grupo minero & Títulos & Volumen extraido $\left(\mathrm{m}^{3} / \mathrm{a}\right)$ \\
\hline Grupo México, S.A.B. de C.V. & 142 & 90616942.80 \\
\hline Goldcorp Inc. & 74 & 47656034.00 \\
\hline Arcelor Mittal México, S.A. de C.V. & 11 & 45844982.00 \\
\hline Primero Mining Corporation & 4 & 29417231.00 \\
\hline Pondercel, S.A. de C.V. & 21 & 26110478.00 \\
\hline Altos Hornos de México, S.A. de C.V. & 29 & 23339103.00 \\
\hline Ternium México, S.A. de C.V. & 37 & 16951194.00 \\
\hline Cemex, S.A.B. de C.V. & 48 & 12903727.95 \\
\hline Minera Frisco, S.A.B. de C.V. & 36 & 10251007.00 \\
\hline Mexichem, S.A.B. de C.V. & 22 & 9365360.00 \\
\hline Tubos de Acero de México, S.A. & 10 & 7518570.00 \\
\hline Consorcio Minero Benito Juárez Peña Colorada, S.A. de C.V. & 9 & 6892901.00 \\
\hline Florentino Rivero Rodríguez & 17 & 6082500.00 \\
\hline Fresnillo PLC & 15 & 5647991.00 \\
\hline Las Encinas, S.A. de C.V. & 12 & 5020285.16 \\
\hline
\end{tabular}

Fuente: Cartocrítica, «Concesiones de agua para las mineras», 2016, http://www.cartocritica.org.mx/2016/concesiones-de-agua-para-las-mineras/

Relativo al saqueo del agua para beneficio de los grandes corporativos mineros de capital transnacional, se toman los datos de las tres empresas mineras que más consumen en el país: Grupo México, Goldcorp y Arcelor Mittal México. En conjunto el consumo anual ascendió a 184.11 millones de $\mathrm{m}^{3},{ }^{28}$ suficiente para abastecer a 5 millones 44 mil 327 personas (117 por ciento del total de la población de Aguascalientes, Durango y Zacatecas, que suma 4 millones 308 mil 598 habitantes).

La problemática del agua en México asociada al despojo de las empresas transnacionales mineras se agudiza, debido a la presión hídrica de contribuir con 431 millones de $\mathrm{m}^{3}$ por quinquenio al monto de la deuda de agua a Estados Unidos, para dar cumplimiento al Tratado de Distribución de Aguas Internacionales, signado en $1944 .{ }^{29}$

Cada vez es más visible la privatización del agua que favorece a otros sectores del capital

${ }^{28}$ Cartocrítica, op. cit.

${ }^{29}$ Gian Carlo Delgado, op. cit. privado y que tiene lugar en el negocio del tratamiento de aguas residuales, ámbito en el que participa la empresa Ondeo-Degremont, así como en el mercado de agua potable embotellada natural y endulzada, dominado por Coca-Cola, Pepsico, Danone y Nestlé. Lo anterior se vincula con la percepción de desconfianza que los mexicanos tienen sobre la calidad del agua que suministra la red pública abastecida por el gobierno, al grado que en 2014

México fue el año pasado el principal consumidor de agua embotellada en el mundo (...) Tres empresas concentran 82 por ciento del mercado de agua embotellada en México: la francesa Danone y las estadounidenses Coca-Cola y PepsiCo (...) De acuerdo con una estimación de la revista Forbes del año pasado, las ventas de agua embotellada de las principales empresas en México alcanzarán los 13 mil millones de dólares en 2015. ${ }^{30}$

\footnotetext{
${ }^{30}$ Juan Paullier, «Por qué México es el país que más agua embotellada consume en el mundo», BBC Mundo, 2015, http:// www.bbc.com/mundo/noticias/2015/07/150722_mexico_consumo_agua_embotellada_jp
} 
Delgado insiste que para facilitar la mercantilización del agua varios organismos internacionales (como el BM) han establecido recomendaciones y directrices que inciden en la privatización de la Conagua. Así, desde febrero de 2015 se presentó en las Cámaras de Diputados y de Senadores del Congreso de la Unión una iniciativa de la Ley General de Aguas Nacionales, llamada Ley Korenfeld, con la que se violentaba el derecho humano al agua de los mexicanos; como ocurre en los municipios de Aguascalientes, Saltillo, Cancún y Puebla, donde se privatizó el servicio de suministro de agua potable y el tratamiento de aguas residuales.

\section{Conclusiones}

La información presentada acerca de la mercantilización delagua en el planointernacional esclareció la tendencia al control de los recursos hídricos por el capital privado transnacional bajo distintas modalidades:

1. Financiarización del agua mediante el acaparamiento de tierras y la compra de concesiones por parte de los principales bancos del mundo bajo las directrices de organismos internacionales.

2. Acuerdos de cooperación y tratados de

La megaminería se ubica entre las industrias con mayor consumo de recursos hídricos.
ción del agua como bien común a mercancía en beneficio de las economías desarrolladas y en perjuicio del Sur global.
3. Control de la cadena de extracción y suministro del agua en manos de empresas transnacionales con sede corporativa en Estados Unidos, España, Francia e Inglaterra. Además, dichas empresas, como Monsanto Wells, se apropian de tecnologías y servicios de proveeduría del agua del planeta.

En cuanto a la turbulencia que genera la megaminería en territorio mexicano, una prueba contundente de que la industria minera provoca graves impactos ambientales se documentó con los datos de Conagua y Cartocrítica, que demostraron las consecuencias ambientales por despojo hídrico. Se indicó que 197 megaproyectos mineros en producción, del total de 1 mil 189, han sido suficientes para saquear el agua indispensable que debe abastecer a diez de cada cien mexicanos.

A fin de detener esa situación, las instituciones académicas de educación superior del país y las organizaciones de la sociedad civil tendrían que respaldar la iniciativa ciudadana de Ley General de Aguas Nacionales, promovida por Agua para Todos, Agua para la Vida. La iniciativa propone frenar la privatización del agua, evitar que las empresas mineras transnacionales ostenten un consumo preferente y que se respete el derecho humano al agua; como sucede en la actualidad en Costa Rica, donde la ley lo protege.

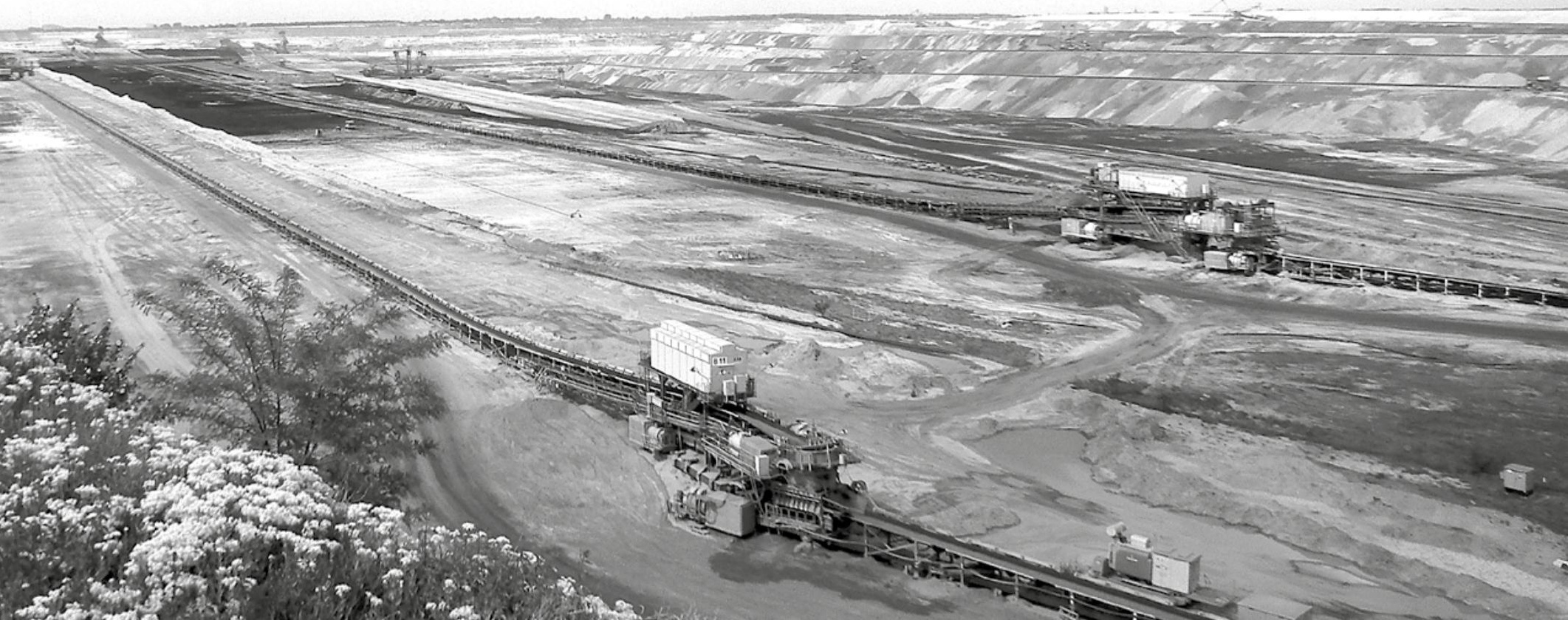

